
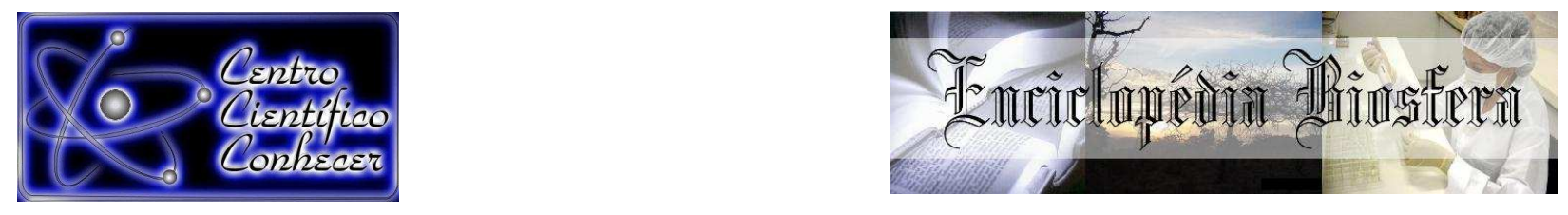

\title{
MONITORAMENTO DOS NÍVEIS DE ATAQUE DE Sirex noctilio POR MEIO DA UTILIZAÇÃO DE ÁRVORES-ARMADILHA E AMOSTRAGEM SEQUENCIAL
}

\author{
Silvio Carolo Junior ${ }^{1}$, Daniele Ukan² \\ 1 Doutorando do Programa de Pós-graduação em Ciências Florestais da \\ Universidade Estadual do Centro-Oeste do Paraná (silviocarolojr@hotmail.com), \\ UNICENTRO, Irati. \\ 2 Professora Doutora do Departamento de Entomologia da Universidade Estadual \\ do Centro-Oeste do Paraná, UNICENTRO, Irati. \\ Recebido em: 08/04/2016 - Aprovado em: 30/05/2016 - Publicado em: 20/06/2016 \\ DOI: 10.18677/Enciclopedia_Biosfera_2016_071
}

\begin{abstract}
Sirex noctilio (Hymenoptera:Siricidae) comumente chamado de vespa-da-madeira é um inseto que causa danos irreversíveis aos plantios de Pinus, pois ataca árvores estressadas levando-as a morte. Para determinar o nível de ataque desta praga é realizado o monitoramento, comumente pela utilização de árvores-armadilhas ou pela amostragem sequencial. Objetivou-se determinar a porcentagem de árvores atacadas pela Sirex noctilio em duas metodologias de monitoramento. Foram instalados no mês de setembro, cinco grupamentos de árvores-armadilha, as quais foram inspecionadas no mês de junho do ano subsequente, sendo que cada grupamento foi composto por cinco árvores, estressadas artificialmente, com o herbicida 2,4-D amina + picloran. A amostragem sequencial foi realizada no mês de maio em cinco talhões de aproximadamente 10 hectares cada em um povoamento de Pinus taeda, conduzido sem um regime de desbaste, no município de Palmas no estado do Paraná. Avaliando as árvores-armadilha constatou-se que $40 \%$ das mesmas apresentavam sintomas de ataque ocasionados pela postura da fêmea da vespa-da-madeira, enquanto que na amostragem sequencial o percentual de árvores atacadas foi $0,51 \%$. Nas árvores atacadas pela $S$. noctilio foi realizado o controle biológico com o nematóide Deladenus siricidicola, o qual é o principal agente de controle biológico desta praga.
\end{abstract}

PALAVRAS-CHAVE: Controle biológico, métodos de avaliação, vespa-da-madeira.

\section{MONITORING ATTACK Sirex noctilio LEVELS THROUGH USE OF THE TREES- TRAP AND SAMPLING SEQUENTIAL}

\begin{abstract}
Sirex noctilio (Hymenoptera: Siricidae) commonly known as wood-wasp, is an insect that causes irreversible damages to pine plantations, such as attacking stressed trees causing their death. To determine the level of attack of the pest a monitoring is performed, usually by using trees-trap or by sequential sampling. Aims to determine the percentage of trees attacked by Sirex noctilio in two monitoring methodologies. Were installed in September, five groups of trees-trap, which were inspected in June of the following year, and each grouping was composed by five trees, stressed
\end{abstract}


artificially with the herbicide 2,4-D amine + picloran. The sequential sampling was carried out in May in five plots of approximately 10 hectares each in a stand of Pinus taeda, conducted without a thinning regime in the city of Palmas in the state of Paraná. Assessing the trees-trap it was found that $40 \%$ of them had attack symptoms caused by posture of female wood-wasp, while at sequential sampling the percentage of attacked trees was $0.51 \%$. It conducted the chi-square test which showed no statistical difference between the tested methodologies. On the trees attacked by $S$. noctilio was conducted a biological control with the nematode Deladenus siricidicola, which is the main biological control agent of this pest.

KEYWORDS: wood-wasp, evaluation methods, biological control.

\section{INTRODUÇÃO}

No ano de 1947 o gênero Pinus foi trazido ao Brasil e desenvolveu-se muito bem na região sul devido às condições climáticas (SNIF, 2015). De acordo com IBÁ (2015), a área de plantio de Pinus no Brasil é de 1,59 milhão de ha, sendo que o estado do Paraná possui $42,4 \%$ deste total. No entanto, quando estes plantios são implantados e conduzidos sem as devidas técnicas, os mesmos tornam-se locais ideais para o surgimento de pragas florestais. Dentre as principais pragas florestais do Pinus, pode-se citar a Sirex noctilio, popularmente conhecida como vespa-damadeira.

A vespa-da-madeira é atraída preferencialmente por plantios estressados, ou seja, povoamentos florestais que não ocorreram desbastes ou estão atrasados, aliados a sítios de baixa produtividade (PENTEADO et al., 2014). Os principais danos provenientes do ataque de $S$. noctilio são as galerias causadas pelas larvas que se desenvolvem no interior da madeira, as manchas azuladas ocasionadas por fungos oportunistas do gênero Botryodiplodia e os orifícios de emergência, provocados pelos insetos adultos que perfuram a madeira para sua emergência (EMBRAPA FLORESTAS, 2011).

Durante a postura, além dos ovos, a fêmea introduz na árvore também os esporos de um fungo simbionte, Amylostereum areolatum e uma mucosecreção. $O$ fungo e o muco são tóxicos à planta e muitas das árvores atacadas podem apresentar clorose das acículas em torno de 10 a 14 dias após o ataque, sendo que o progresso desta clorose depende da intensidade do ataque e da suscetibilidade da árvore hospedeira (PENTEADO et al., 2002).

De acordo COSTA et al. (2014) S. noctilio desenvolve-se por metamorfose completa (holometabolia), ou seja, possui as fases de ovo, larva, pupa e adulto. Os ovos são brancos, alongados com superfície lisa, colocados a uma profundidade média de 12 mm (EMBRAPA FLORESTAS, 2011). IEDE et al. (1988) descrevem as larvas como cilíndricas, de coloração esbranquiçada, com três pares de patas torácicas; vestigiais e um pequeno espinho marrom-avermelhado na região supraanal. As mandíbulas são fortes e de coloração marrom-avermelhada.

$\mathrm{Na}$ fase de pré-pupa, as larvas tendem a se aproximar da região cambial da madeira, onde escavam suas câmaras pupais (COSTA et al., 2014). Durante o processo de alimentação, as larvas constroem galerias no interior da árvore, afetando a qualidade da madeira e também favorecendo a penetração de agentes secundários, o que limita seu uso ou a torna imprópria para o mercado (PENTEADO et al., 2014).

Para evitar a disseminação e os danos da vespa-da-madeira recomenda-se adotar o controle silvicultural, principalmente por meio da realização de desbaste 
ocasionais e seletivos, importantes para impedir sua distribuição, pois povoamentos bem conduzidos e bem manejados não sofrem perdas econômicas (COSTA et al., 2014). Outras medidas importantes são: evitar a realização da poda, pelo menos dois meses antes e durante o período de vôo do inseto, não transportar a madeira atacada para áreas sem a presença do inseto e adotar medidas de sanidade florestal, eliminando-se restos de desbastes com diâmetro superior a cinco centímetros (EMBRAPA FLORESTAS, 2011). Além do método silvicultural, não se pode deixar de citar o controle biológico que é o principal método de controle da vespa-da-madeira, quando esta já está instalada no povoamento. O método consiste na introdução do nematóide Deladenus siricidicola e pelo parasitóide de ovos e larvas Ibalia leucospoides.

Outro fator importante a ser considerado no estudo da $S$. noctilio é o seu monitoramento, que pode ser realizado por meio de árvores-armadilha ou da amostragem sequencial. A amostragem auxilia na definição da dimensão da área atacada, bem como a dispersão anual da vespa-da-madeira.

As árvores-armadilha são grupamento de árvores estressadas artificialmente, utilizando um herbicida. Devem cobrir toda a área do reflorestamento e serem instaladas em locais de fácil acesso para facilitar a sua posterior inspeção, onde as árvores são derrubadas para a retirada de três toretes de cada árvore e verificado sintomas de ocorrência como serragem compactada e a presença da própria larva da S. noctilio (PENTEADO et al., 2002).

A amostragem sequencial consiste em uma alternativa utilizada no monitoramento de $S$. noctilio, em que a cada 50 ha se devem realizar uma amostragem. Como a amostragem sequencial é dimensionada no campo em virtude dos níveis de ataque, não ocorre à falta de precisão no tamanho das amostras, por isso, esta metodologia é uma das mais viáveis no cenário atual (PENTEADO et al., 2002). Diante do exposto, objetivou-se determinar a porcentagem de árvores atacadas pela Sirex noctilio utilizando duas metodologias de monitoramento.

\section{MATERIAL E MÉTODOS}

\section{Localização da Área de Estudo}

O presente estudo foi desenvolvido em um povoamento de Pinus taeda (26을

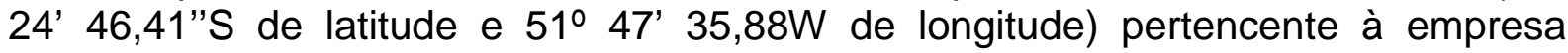
Reflorasul Agroflorestal S.A., no município de Palmas - PR. A temperatura média anual na cidade é de $1^{\circ} \mathrm{C}$ e precipitação de $\mathrm{x} \mathrm{mm}$. O clima da região segundo a classificação de Köppen é Cfb.

O povoamento possui uma área total de 410 ha, sendo que 117 são plantios de $P$. taeda com 13 anos de idade, densidade de 1600 árvores/ha (espaçamento de $2.5 \times 2.5 \mathrm{~m}$ ), sem a ocorrência de desbaste e sem a realização de poda.

\section{Instalação das árvores-armadilha}

Para o monitoramento da vespa-da-madeira foram instalados cinco grupos de árvores-armadilha, no mês de setembro.

As árvores-armadilha foram instaladas na densidade de um grupo de árvoresarmadilha para cada 25 ha. Estas foram instaladas nas bordas dos talhões, margeando estradas e aceiros, para facilitar a posterior inspeção.

Cada grupo de árvores-armadilha foi composto por cinco árvores, e para tanto foram escolhidas aquelas que já apresentavam alguma deformidade, como ENCICLOPÉDIA BIOSFERA, Centro Científico Conhecer - Goiânia, v.13 n.23; p. 8242016 
dominadas, bifurcadas ou tortas. As árvores foram selecionadas aleatoriamente independente de estarem alinhadas.

O estressamento das árvores-armadilha deu-se por meio da utilização do herbicida 2,4-D amina + picloran a concentração de $20 \%$ e anelamento das árvores, adaptando as recomendações de PENTEADO et al. (2002). O anelamento foi feito com um facão a 1,30 $\mathrm{m}$ de altura do solo. Para aplicar o herbicida foram realizados entalhes na árvore utilizando uma machadinha, sendo quatro entalhes por árvore e em cada um deles foi colocado $2 \mathrm{ml}$ da solução com o auxilio de uma seringa descartável, totalizando oito $\mathrm{mL}$ por árvore que compõe o grupo de árvoresarmadilha.

\section{Inspeção das árvores-armadilha}

A inspeção das árvores-armadilha foi realizada em junho, nove meses após a instalação. Nesta etapa as árvores foram derrubadas com motosserra e traçadas do terço médio ao terço superior do tronco, retirando-se de dois a três toretes por árvore com aproximadamente $30 \mathrm{~cm}$ cada. Utilizando-se de um machado, os toretes foram rachados ao meio para observar a presença de larvas e galerias de S. noctilio no seu interior.

\section{Amostragem Sequencial}

A amostragem sequencial foi realizada em maio, oito meses após a instalação. Esta ocorreu nos mesmos talhões em que foram instaladas as árvoresarmadilha. A amostragem sequencial foi realizada em cinco talhões distintos, tendo em vista que os mesmos têm uma área de aproximadamente 10 ha cada. Para a realização da amostragem sequencial seguiu-se metodologia proposta por PENTEADO et al. (2002).

As árvores atacadas foram identificadas pela coloração marrom das acículas e pela presença de respingos de resina no tronco, principalmente no terço médio e a parte inferior do terço superior. Caso ainda restassem dúvidas, as árvores eram derrubadas, retirando-se pequenos toretes e verificando-se a presença de galerias, serragem compactada e a própria larva da $S$. noctilio.

O porcentual de ataque foi calculado pela seguinte fórmula (PENTEADO et al., 2002).

$$
\% \text { de ataque }=\frac{\mathrm{n}^{\circ} \text { de árvores atacadas }}{\mathrm{n}^{0} \text { de árvores amostradas }} \times 100
$$

Tanto as árvores da amostragem sequencial quanto das árvores-armadilha, em que se observaram os sintomas de ataque ocasionados pela $\mathrm{S}$. noctilio, foram inoculadas com o nematóide Deladenus siricidicola. Para a preparação do inóculo e a aplicação nas árvores seguiu-se as recomendações de PENTEADO et al. (2002).

\section{RESULTADOS E DISCUSSÃO Avaliação do ataque nas árvores-armadilha \\ Avaliando-se os grupos de árvores-armadilha instalados no experimento, constatou-se que $40 \%$ das árvores estressadas apresentavam sintomas de ataque de S. noctilio, como pode ser observado na Tabela 1.}


TABELA 1. Porcentagem de árvores atacadas por $S$. noctilio nos grupos de árvoresarmadilha, Palmas - PR.

\begin{tabular}{ccc}
\hline Grupo de árvores-armadilha & № de árvores atacadas & $\%$ \\
\hline 1 & 2 & 40 \\
2 & 1 & 20 \\
3 & 5 & 100 \\
4 & 1 & 20 \\
5 & 1 & 20 \\
\hline Média & $\mathbf{2}$ & $\mathbf{4 0}$ \\
\hline
\end{tabular}

Cada grupo de árvores armadilhas possui cinco árvores.

O alto porcentual de árvores atacadas encontradas nas árvores-armadilha pode ser resultado da falta de intervenções na floresta, pois, até o momento não ocorreu nenhum desbaste. Para verificar o nível de ataque de $S$. noctilio no povoamento de $P$. taeda, foi realizada a amostragem sequencial. A porcentagem média de ataque foi $0,51 \%$ conforme demonstrado na Tabela 2 .

TABELA 2. Porcentagem de árvores atacadas por $S$. noctilio encontradas na amostragem sequencial, Palmas - PR.

\begin{tabular}{ccc}
\hline Amostragem sequencial & Node árvores atacadas & $\%$ \\
\hline 1 & 2 & 0,74 \\
2 & 1 & 0,37 \\
3 & 2 & 0,74 \\
4 & 2 & 0,74 \\
5 & 0 & 0,00 \\
\hline Média & $\mathbf{1 , 4}$ & $\mathbf{0 , 5 1}$ \\
\hline
\end{tabular}

A amostragem sequencial foi composta de 272 árvores.

Nota-se observando os valores da Tabela 2 que na primeira, na terceira e na quarta amostragem foram encontradas duas árvores atacadas, no segundo caminhamento foi encontrado apenas uma árvore com sintomas de ataque de $S$. noctilio. Na realização da quinta amostragem sequencial nenhuma árvore foi encontrada com indícios de ataque. A porcentagem de árvores atacadas foi de $0,74 \%, 0,37 \%, 0,74 \%, 0,74 \%$ e $0,00 \%$ nos caminhamentos $1,2,3,4$ e 5 respectivamente.

Realizou-se o teste de qui-quadrado utilizando os valores relativos das árvores-armadilha e da amostragem sequencial, com o intuito de correlacioná-las. De acordo com o teste conclui-se que não há diferença entre as metodologias de monitoramento. O qui-calculado $\left(4,75 \times 10^{-41}\right)$ foi menor que o qui-tabelado ao nível de $5 \%$ de probabilidade $(9,49)$, ou seja, pode-se dizer que as duas formas de avaliação da população de $S$. noctilio nos povoamentos florestais são satisfatórias e não possuem diferenças estatísticas.

Nota-se que na amostragem sequencial 0 ataque de $S$. noctilio não ultrapassou 1\%. Segundo EMBRAPA FLORESTAS (2011), a instalação de árvoresarmadilha deverá ser realizada enquanto a porcentagem de ataque estiver abaixo de 
1\%. Acima deste valor deve-se usar a amostragem sequencial, como método de monitoramento.

Cabe ressaltar que o número de árvores atacadas pela vespa-da-madeira nas árvores-armadilha foi superior aos da amostragem sequencial, pois no primeiro método as árvores utilizadas como armadilhas são estressadas artificialmente,ou seja, são induzidas a se tornarem atrativas ao inseto, enquanto que na amostragem sequencial o ataque dá-se naturalmente.

Em relação às árvores atacadas por $S$. noctilio encontradas em ambas as metodologias considera-se que: quanto maior o número de árvores atacadas haverá mais locais de inoculação do nematóide, desta forma a chance de disseminação do controle biológico é maior, uma vez que as fêmeas parasitadas ajudarão a dispersar o patógeno. Outro fator evidenciado foi que há a necessidade de se adotar um programa de manejo integrado de pragas, utilizando-se o controle biológico, bem como o silvicultural.

Quando um povoamento é conduzido sem um regime de manejo que envolva desbastes sistemáticos ou seletivos, o mesmo apresenta um maior número de árvores por hectare, gerando assim maior concorrência entre as árvores e consequentemente um maior estresse no povoamento, tornando-se locais propicios para o estabelecimento da vespa-da-madeira, quando comparada a povoamentos conduzidos com um regime de desbastes. Além disso, em povoamentos conduzidos sem desbaste a estagnação das variáveis dendrométricas é antecipado, consequentemente a fitossanidade do povoamento é afetada.

\section{CONCLUSÕES}

Ambas as metodologias (árvores-armadilha e amostragem sequencial) mostraram-se eficientes para o monitoramento da $S$. noctilio, além de servirem de pontos estratégicos para a inoculação e liberação dos inimigos naturais, entretanto devido ao baixo percentual de ataque encontrado na amostragem sequencial, devem-se utilizar as árvores-armadilhas como forma de monitoramento.

\section{REFERÊNCIAS}

COSTA, E.C.; D'AVILA, M.; CANTARELLI, E. B.; MURARI A. B. Entomologia Florestal. 3a ed. Santa Maria: UFSM, 2014. 256p

EMBRAPA FLORESTAS. Vespa-da-madeira. Colombo, 2011. Fôlder.

IBÁ, 2015. Relatório IBÁ, 2015. Indústria Brasileira de Árvores. Ano base 2014. Brasília, 2015. 80p. Disponível em <http://www.ipef.br/estatisticas/relatorios/anuarioiba_2015.pdf>. Acesso em: 27 de maio de 2016.

IEDE, E.T.; PENTEADO, S. do R. C.; BISOL, J.C. Primeiro registro de ataque de Sirex noctilio em Pinus taeda no Brasil. Colombo: EMBRAPA - CNPF, 1988. 12p. (EMBRAPA - CNPF, Circular Técnica, 20).

PENTEADO, S. do R. C.; IEDE, E. T.; REIS FILHO, W. Manual para o controle da vespa-da-madeira em plantio de pinus. Embrapa Florestas. Documentos 76, 38p. 2002. 
PENTEADO, S. do R. C.; PENTEADO JUNIOR, J. F.; BUHRER, C. de B.; POSANSKI, R. G. Custo de aplicação do inóculo de nematoide, em gelatina e em hidrogel, para o controle da vespa-da-madeira. Comunicado Técnico 341. Colombo - PR. 2014.

SNIF - SISTEMA NACIONAL DE INFORMAÇÕES FLORESTAIS. As florestas plantadas. Disponível em: <http://www.florestal.gov.br/snif/recursos-florestais/asflorestas-plantadas>. Acesso em: 23 maio 2015. 